\title{
Neuropathic diabetic foot ulcers - evidence-to-practice
}

This article was published in the following Dove Press journal:

International Journal of General Medicine

10 February 2012

Number of times this article has been viewed

\section{Agbor Ndip ${ }^{1-3}$}

Leonard Ebah ${ }^{3,4}$

Aloysius Mbako ${ }^{5}$

'Department of Diabetes and Medicine, Manchester Royal Infirmary, Central Manchester Foundation Trust, UK; ${ }^{2}$ Department of Medicine, Royal Bolton Hospital, Bolton, UK; ${ }^{3}$ Cardiovascular Research Group, School of Biomedicine, University of Manchester, UK; ${ }^{4}$ Department of Renal Medicine, Manchester Royal Infirmary, Central Manchester Foundation Trust, UK; ${ }^{5}$ Department of Orthopaedic Surgery, Wrexham Maelor Hospital, Wales, UK

Video abstract

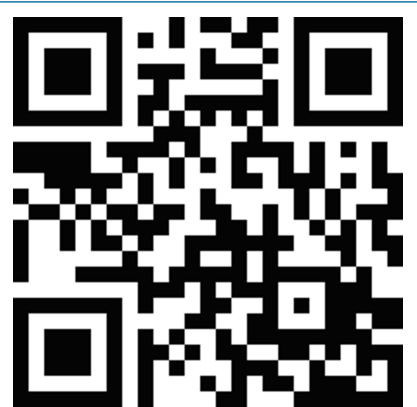

Point your SmartPhone at the code above. If you have a QR code reader the video abstract will appear. Or use: http://dvpr.es/zlflff

Correspondence: Agbor Ndip Department of Diabetes and Medicine, Manchester Royal Infirmary, Central Manchester Foundation Trust (CMFT), Manchester, UK Email agbor.ako@manchester.ac.uk
Abstract: Foot ulcers and their attendant complications are disquietingly high in people with diabetes, a majority of whom have underlying neuropathy. This review examines the evidence base underpinning the prevention and management of neuropathic diabetic foot ulcers in order to inform best clinical practice. Since it may be impractical to ask patients not to weight-bear at all, relief of pressure through the use of offloading casting devices remains the mainstay for management of neuropathic ulcers, whilst provision of appropriate footwear is essential in ulcer prevention. Simple non-surgical debridement and application of hydrogels are both effective in preparing the wound bed for healthy granulation and therefore enhancing healing. Initial empirical antibiotic therapy for infected ulcers should cover the most common bacterial flora. There is limited evidence supporting the use of adjunctive therapies such as hyperbaric oxygen and cytokines or growth factors. In selected cases, recombinant human platelet-derived growth factor has been shown to enhance healing; however, its widespread use cannot be advised due to the availability of more cost-effective approaches. While patient education may be beneficial, the evidence base remains thin and conflicting. In conclusion, best management of foot ulcers is achieved by what is taken out of the foot (pressure, callus, infection, and slough) rather than what is put on the foot (adjuvant treatment).

Keywords: diabetic foot ulcers, neuropathic foot ulcers, foot ulcers

\section{Introduction}

\section{Definition}

Diabetic foot ulcers (DFUs) are chronic ulceration (break in the continuity of the skin) occurring in the feet of people with diabetes. It has been estimated that one in every four patients with diabetes will develop a foot ulcer during their lifetime. ${ }^{1}$

\section{Etiology}

Foot ulceration in diabetes can either be associated with neuropathy (neuropathic ulcer), peripheral vascular disease (ischemic ulcer), or both (neuroischemic ulcer), although the final etiopathogenetic pathway may involve a combination of these primary risk factors and other causal factors such as trauma. ${ }^{2}$ However, up to $85 \%$ of DFUs are associated with neuropathy ${ }^{3}$ while between $10 \%-60 \%$ are associated with ischemia, depending on the studies considered. ${ }^{4}$ Neuropathic ulceration is usually orchestrated by foot deformity, high foot pressures, reduced soft tissue padding, and unattended or unnoticed trauma, entraining tissue damage. Once tissue breakdown occurs, the resultant ulceration becomes chronic as the insensate foot fails to convey nociceptive stimuli which are necessary to provoke protective behavior. 


\section{Economics}

In the US in 1999, the cost attributable to a new foot ulcer for a 40-65-year-old male was estimated at $£ 19,000$ in the 2 years after diagnosis, ${ }^{5}$ whilst in Sweden, the cost of healing a foot ulcer in 1997 was $£ 11,000$ without amputation and $£ 21,000$ for a major amputation. ${ }^{6}$ More recently, in the Eurodiale study the total cost (direct and indirect) of treatment of a diabetic foot ulcer varied from $£ 3500$ for non-infected neuropathic ulcers to $£ 13,000$ for infected ischemic ulcers. ${ }^{7}$

\section{Search sources}

The following sources were used during this review: PubMed, Cochrane Library, NHS evidence, clinical evidence, OVID, EMBASE.

\section{Level of evidence used}

Meta-analysis, systematic reviews, randomized controlled trials (RCT), prospective studies.

\section{Outcomes}

Healing of diabetic foot ulcers. Prevention of new foot ulcers or re-ulceration.

\section{Consumer summary}

Foot ulcers are common in diabetics. One of the main causes of these ulcers is neuropathy (nerve damage), making it difficult for the person to identify damage to their feet such as cuts, bruises, and pressure. We have researched various published studies to see which specific treatments are best indicated for DFUs. We found that casting (wrapping a hard fiberglass material such as plaster of Paris) can help enhance the healing of DFUs by reducing the amount of pressure on the wound, thus minimizing further tissue breakdown. Also, the manual removal of dead tissue and slough (a procedure called debridement) by a foot specialist such as a podiatrist can enhance wound healing. If the wound is infected, simple antibiotics can be prescribed to control infection. There is little evidence to support the use of other agents on the wound, some of which can be very expensive. Education of patients may reduce their chances of developing an ulcer, but this has to be done alongside other preventive measures.

\section{Research questions}

This review sought to critically appraise the available evidence in order to answer the specific questions:

1. What therapies/interventions are effective in speeding wound healing or increasing the proportion of healed diabetic foot ulcers?
2. What interventions are effective in the prevention of diabetic foot ulcers?

\section{The evidence}

Therapies/interventions that enhance wound healing

Pressure relieving casts in the management of DFUs

We found one Cochrane review that concluded that total contact casting (TCC) is effective in healing ulcers. ${ }^{8}$ The trial of TCC only involved 40 people for 6 weeks and rates of infection and hospitalizations would need to be considered for longer term use. The same review concluded that there is no available evidence for the use of removable casts in the healing of foot ulcers. Similarly, we could not find any evidence to support the use of other forms of casting such as soft casts and scotchcast boots.

\section{Debridement}

A Cochrane review reported on the role of debridement on DFUs. ${ }^{9}$ Six RCTs of debridement were identified: four assessed hydrogels, with an additional study evaluating larval therapy against hydrogel, and one evaluated surgical debridement. Pooling the three RCTs which compared hydrogel with gauze or standard care suggested that hydrogels are significantly more effective in healing DFUs. Surgical debridement showed no significant benefit over standard debridement. ${ }^{10}$ One small trial, available only in abstract form, suggested that larvae resulted in a greater reduction in wound area compared with hydrogel, but 10 years on, the full trial results have yet to be published. ${ }^{11}$ A small prospective but non-randomized study of 13 subjects with methicillinresistant Staphylococcus aureus colonized DFUs reported that application of maggots eradicated methicillin-resistant S. aureus in 12 out of the 13 wounds. ${ }^{12}$ Other debridement methods such as enzyme preparations or polysaccharide beads have not been evaluated in DFUs.

\section{Wound dressing}

The enormous variety of types of wound dressing is not matched by robust evidence. A recent Cochrane review undertaken to compare silver-based wound dressings versus topical agents for treating DFUs concluded that no studies were found that were suitable for inclusion.

\section{Role of vacuum-assisted closure (VAC) of wounds}

Vacuum-assisted closure using negative topical pressure (125 mmHg) is a resurgent therapy in foot ulcer care. ${ }^{13-15}$ Although VAC remains a relatively safe modality for treatment 
of diabetic foot wounds, two Cochrane reviews of studies examining the use of VAC in diabetic foot wounds have concluded that the current evidence base is only supported by a limited number of under-powered, poorly-designed studies. ${ }^{16,17}$

\section{Adjunctive therapies in the management of diabetic foot lesions \\ Platelet-derived growth factor (PDGF)}

We found four multicenter RCTs assessing the role of lyophilized recombinant human PDGF, beta-beta homodimer (rhPDGF-BB), purified from genetically engineered yeast in the treatment of chronic non-infected non-ischemic DFUs and one non-systematic review. ${ }^{18}$ All patients in the RCTs received standard care including adequate debridement. The first RCT was a Phase II company-led (Johnson and Johnson) trial $^{19}$ whilst the others were Phase III trials. ${ }^{20}$ The probability of complete wound healing was significantly higher with rhPDGF-BB gel compared with placebo gel treatment. Treatment with rhPDGF-BB gel also significantly decreased the time to complete healing by $30 \%$. Adverse events and ulcer recurrence rates were similar in both treatment groups.

\section{Granulocyte colony-stimulating factor (G-CSF)}

Cruciani et al performed a meta-analysis to examine the role of G-CSF added to usual care on rates of infection, cure, and wound healing in people with diabetes who have a foot infection. $^{21,22}$ They found that adding G-CSF did not significantly affect the likelihood of resolution of infection or wound healing, but was associated with reduced lower extremity surgical interventions, including amputation. Additionally, G-CSF reduced the duration of hospital stay, but did not affect the duration of systemic antibiotic therapy.

\section{Honey}

Although honey has been used since antiquity in the treatment of chronic ulcers, there is a striking lack of data from carefully designed RCTs or prospective studies. One study suggested equivalence to polyvidone iodine in Wagner grade 2 DFUs, ${ }^{23}$ but the design and statistical analysis of this study failed to use convincing methodologies.

\section{Hyperbaric oxygen therapy (HBOT)}

Two independent systematic reviews on HBOT concluded that systemic HBOT may reduce the incidence of major amputation in people with DFUs. ${ }^{24,25}$ However, most of the studies evaluated were relatively small. Therefore, further evidence is required from larger, more robust, and blinded studies.
Nonetheless, systemic HBOT may be considered in patients with ischemic ulcers and where revascularization is not possible. The benefit of topically administered HBOT has not been established.

\section{Empirical antibiotics in the treatment of diabetic foot infections}

We found no RCTs or systematic reviews that examined different antimicrobial agents as empirical treatment for diabetic foot infections. However, one open-labeled randomized study compared the efficacy and safety of intravenous and oral formulations of linezolid to intravenous ampicillinsulbactam and intravenous and oral amoxicillin-clavulanate, based on the premise that aerobic Gram-positive cocci are the most frequent and virulent pathogens. ${ }^{26}$ In this study, overall clinical cure rates associated with linezolid and the comparator antibiotics were statistically equivalent.

\section{Therapies/interventions that prevent new ulcers or recurrent ulceration}

\section{Therapeutic shoes in the prevention of DFUs in at-risk patients}

A Cochrane review on the use of pressure relieving footwear in the prevention of DFUs concluded that whilst trials using customized insoles have shown some benefit, it is not possible to recommend any particular type of orthotic device (cushioning or pressure redistribution). ${ }^{8}$

\section{Education and self-care practices}

A Cochrane review of educational interventions in the prevention of DFUs concluded that most of the RCTs included in the review were at high or unclear risk of bias. In some trials, foot care knowledge and self-reported patient behavior seem to be positively influenced by education in the short term. The ultimate goal of educational interventions should be prevention of DFUs and amputation but only four RCTs reported these outcomes and only two reported sufficient data to examine this. There was insufficient robust evidence from these two studies that patient education alone is effective in achieving reductions in clinically relevant outcomes. Several studies to evaluate diabetic foot education also incorporate other standard prevention strategies such as education of primary care physicians and recommendations for consultations for high-risk patients for foot care and protective shoes. ${ }^{27,28}$

In fact, results of clinical studies report conflicting results. Malone et al conducted a prospective randomized clinical study to evaluate the influence of education on lower extremity amputations. During the follow-up period there 
were significantly fewer ulcerations and amputations in the education arm. ${ }^{29}$ Litzelman et al also randomized 395 patients with diabetes assigned to either a multifaceted education and prevention program or usual care. Patients in the intervention group were less likely to have foot ulcers and more likely to report recommended self-care practices. ${ }^{27}$

In contrast, Lincoln et al found that education improved knowledge, but there was no difference in foot ulcers or amputations. They randomized 172 patients with newly healed DFUs to receive usual care or one-to-one education. At 12 months, the incidence of ulceration was the same in both groups $(41 \%){ }^{30}$

\section{Temperature self-assessment}

There are three randomized clinical studies that compare standard prevention therapies consisting of therapeutic shoes and insoles, regular foot care by a podiatrist, and a standard footspecific education to temperature-monitoring intervention ${ }^{31}$ (Table 1). In each of the studies, there was a significant reduction in the incidence of foot ulcerations in the temperature monitoring group; patients in the standard therapy groups had a three- to ten-fold increased risk of developing an ulcer (Table 1).

\section{Fat pad augmentation}

Injectable silicone oil has been used for over 50 years. Prospective studies have demonstrated that injectable silicone significantly increased tissue thickness on the sole of the foot and reduced peak foot pressures in high-risk diabetics compared to placebo-injected controls after 1 and 2 years. ${ }^{32,33}$ We found no prospective randomized studies that demonstrate a change in clinical outcomes such as ulceration or amputation using this approach.

\section{Discussion}

\section{Potential pitfalls}

- Failure to perform inspection on the bare foot (all shoes and socks removed). It is not uncommon for an infected toe ulcer to be missed because it was covered in a small dressing.
- Failure to assess for or recognize ischemia. It is rare to find a "purely neuropathic ulcer" and any evidence of ischemia must prompt urgent vascular assessment and/or referral.

\section{Assessment}

No specialist skills are required for a proper assessment of DFUs. A thorough history should be taken to elicit neuropathy, peripheral vascular disease, renal status (particular attention must be given to dialysis-treated subjects), foot care behavior, foot wear, and any history of psychiatric illness such as anxiety and depression. Physical examination should include assessment for neuropathy using simple tools like the $10 \mathrm{~g}$ monofilament test or the neurothesiometer, or a composite test such as the neuropathic disability score (ankle reflex, vibrating tuning fork test, pinprick sensation, and hot/cold sensation). The foot is assessed for deformity, callus, and other pre-ulcerative lesions or foot ulcers. Footwear must also be assessed for suitability and whether therapeutic footwear is required. Ischemia is assessed by palpation of foot pulses and determination of ankle brachial index (the ratio of the systolic blood pressure at ankle to the systolic blood pressure of the arm). The presence of gangrene, the absence of two or more foot pulses, or an ankle brachial pressure index $<0.9$ should prompt referral for non-invasive vascular tests and/or vascular surgery review to rule out clinically important ischemia that can be considered for revascularization.

\section{Treatment}

The TCC remains effective for offloading neuropathic DFUs. ${ }^{34-36}$ The main issue with the TCC is that its application and removal requires trained personnel and ulcers can sometimes develop within these casts when performed by unskilled persons. Other casting methods may be effective if patients are fully compliant and wear these at all times during weight bearing. ${ }^{37}$ Where compliance is a major concern, these can be made irremovable by additionally wrapping a film of conventional cast. ${ }^{38}$

Table I Temperature studies to prevent re-ulceration

\begin{tabular}{|c|c|c|c|c|c|}
\hline Author & Study population & Study duration & Study groups & Ulceration & $\begin{array}{l}\text { Odds ratio } \\
\text { (confidence interval) }\end{array}$ \\
\hline \multirow[t]{2}{*}{ Lavery $^{39}$} & Foot ulcer history & 6 months & I. Standard therapy & $2 \%$ & 10.3 \\
\hline & & $\mathrm{n}=85$ & 2. Temperature monitoring & $20 \%$ & $(1.2-85.3)$ \\
\hline \multirow[t]{3}{*}{ Lavery ${ }^{40}$} & Foot ulcer history & 15 months & I. Standard therapy & $29.30 \%$ & $4.4(1.5-12.8)$ \\
\hline & & $n=173$ & 2. Structured examination & $30.40 \%$ & $4.7(1.6-13.9)$ \\
\hline & & & 3. Temperature monitoring & $8.50 \%$ & \\
\hline \multirow[t]{2}{*}{ Armstrong ${ }^{31}$} & Foot ulcer history & 18 months & I. Standard therapy & $12.20 \%$ & 3.0 \\
\hline & orneuropathy and deformity & $\mathrm{n}=225$ & 2. Temperature monitoring & $4.70 \%$ & $(1.0-8.5)$ \\
\hline
\end{tabular}


Debridement can be performed by a podiatrist as an outpatient procedure but hydrocolloid gels are equally effective agents for debridement. Debridement involves the careful removal of dead or devitalized tissue and debris/slough, and preparing the wound bed for healthy granulation tissue to develop. Current evidence does not demonstrate superiority of surgical debridement over simple debridement.

For empirical therapy, antibiotics with activity predominantly against Gram-positive organisms (staphylococci and streptococci) $)^{26}$ or broad-spectrum antibiotics with increased activity against Gram-negative organisms and obligate anaerobes $^{39}$ are effective. Amoxicillin-clavulanic acid at a dose of $625 \mathrm{mg}$ three times a day is an effective empirical antibiotic for infected DFUs.

Patient education remains an integral part of management of DFUs although this is based on "common sense" that has not been supported by clear evidence. Nonetheless, education for the prevention of DFUs has to be done in tandem with other preventative measures.

The recombinant growth factor rhPDGF-BB gel is licensed for use in the US. At a dose of $100 \mu \mathrm{g} / \mathrm{g}$, it is effective in non-ischemic non-infected ulcers with an area $<10 \mathrm{~cm}^{2}$. It has a good side-effect profile but its use is likely to be limited by the associated high costs.

Granulocyte colony-stimulating factor may be considered in the treatment of infected DFUs, especially in patients with a limb-threatening infection, but it remains unclear which patients might benefit.

For necrotic, neuropathic sloughy ulcers, topical application of sterile maggots can be used to speed debridement of ulcers and also to eradicate methicillin-resistant $S$. aureus. They can be either free range or applied in bags, but have to be changed every 3-4 days. They are contraindicated in ischemic or neuroischemic foot ulcers where they can cause side effects such as pain. Some patients can be psychologically averse to these "little organisms" and care must be taken to allay any fears or misconceptions.

Notwithstanding, one has to bear in mind that the absence of evidence does not mean evidence of ineffectiveness.

\section{Specialist referral}

- An orthotist or shoemaker must be available on-site to assess on and/or provide appropriate footwear to all patients with neuropathic foot ulcers.

- Patients needing casting devices for offloading should be sent via ambulance to the casting unit if this is not present on-site.
- A non-invasive vascular assessment should be requested and the vascular lab contacted to arrange early vascular studies in all patients with suspected ischemia. Patients who have confirmed lower limb ischemia or present with ischemic gangrene should be considered for revascularization. If this service is not available locally, arrangements should be made for patients to be transferred to the nearest vascular surgery service.

- In recalcitrant infections or limb-threatening infections, discuss with microbiology colleagues for advice on appropriate antimicrobials.

- A foot care program should be offered to patients on dialysis as DFUs are prevalent and can sometimes go undiagnosed.

- Some countries have specific recommendations. In the UK for instance, GPs are advised to refer all diabetic foot patients with an ulcer to a specialized diabetic foot service and to be seen by this team within 24 hours of presentation.

\section{Disclosure}

The authors report no conflict of interest in this work.

\section{References}

1. Singh N, Armstrong DG, Lipsky BA. Preventing foot ulcers in patients with diabetes. JAMA. 2005;293(2):217-228.

2. Reiber GE, Vileikyte L, Boyko EJ, et al. Causal pathways for incident lower-extremity ulcers in patients with diabetes from two settings. Diabetes Care. 1999;22(1):157-162.

3. Boulton AJ. The pathogenesis of diabetic foot problems: an overview. Diabet Med. 1996;13:S12-S16.

4. Ndip A, Jude EB. Emerging evidence for neuroischemic diabetic foot ulcers: model of care and how to adapt practice. Int J Low Extrem Wounds. 2009;8(2):82-94.

5. Ramsey SD, Newton K, Blough D, et al. Incidence, outcomes, and cost of foot ulcers in patients with diabetes. Diabetes Care. 1999;22(3): $382-387$.

6. Tennvall GR, Apelqvist J, Eneroth M. Costs of deep foot infections in patients with diabetes mellitus. Pharmacoeconomics. 2000;18(3): 225-238.

7. Prompers L, Huijberts M, Schaper N, et al. Resource utilisation and costs associated with the treatment of diabetic foot ulcers. Prospective data from the Eurodiale Study. Diabetologia. 2008;51(10):1826-1834.

8. Spencer S. Pressure relieving interventions for preventing and treating diabetic foot ulcers. Cochrane Database Syst Rev. 2000;3:CD002302.

9. Edwards J, Stapley S. Debridement of diabetic foot ulcers. Cochrane Database Syst Rev. 2010;1:CD003556.

10. Piaggesi A, Schipani E, Campi F, et al. Conservative surgical approach versus non-surgical management for diabetic neuropathic foot ulcers: a randomized trial. Diabet Med. 1998;15(5):412-417.

11. Markevich YO, McLeod-Roberts J, Mousley M, Melloy E. Maggot therapy for diabetic neuropathic foot wounds. Diabetologia: Proceedings of the 36th Annual meeting of the European Association for the Study of Diabetes. 2000;43:Supp11:A15.

12. Bowling FL, Salgami EV, Boulton AJ. Larval therapy: a novel treatment in eliminating methicillin-resistant Staphylococcus aureus from diabetic foot ulcers. Diabetes Care. 2007;30(2):370-371. 
13. Joseph E, Hamori CA, Bergman S, Roaf E, Swann NF, Anastasi GW. A prospective randomized trial of vacuum-assisted closure versus standard therapy of chronic nonhealing wounds. Wounds. 2000;12(3): 60-67.

14. Moisidis E, Heath T, Boorer C, Ho K, Deva AK. A prospective, blinded, randomized, controlled clinical trial of topical negative pressure use in skin grafting. Plast Reconstr Surg. 2004;114(4):917-922.

15. Armstrong DG, Lavery LA; Diabetic Foot Study Consortium. Negative pressure wound therapy after partial diabetic foot amputation: a multicentre, randomised controlled trial. Lancet. 2005;366(9498):1704-1710.

16. Eneroth M, van Houtum WH. The value of debridement and vacuumassisted closure (VAC) therapy in diabetic foot ulcers. Diabetes Metab Res Rev. 2008;24 Suppl 1:S76-S80.

17. Ubbink DT, Westerbos SJ, Evans D, Land L, Vermeulen H. Topical negative pressure for treating chronic wounds. Cochrane Database Syst Rev. 2008;3:CD001898.

18. Steed DL. Clinical evaluation of recombinant human platelet-derived growth factor for the treatment of lower extremity ulcers. Plast Reconstr Surg. 2006;117(7 Suppl):143S-149S.

19. Steed DL. Clinical evaluation of recombinant human platelet-derived growth factor for the treatment of lower extremity diabetic ulcers. J Vasc Surg. 1995;21(1):71-81.

20. Wieman TJ, Smiell JM, Su YC. Efficacy and safety of a topical gel formulation of recombinant human platelet-derived growth factor-BB (becaplermin) in patients with chronic neuropathic diabetic ulcers. A phase III randomized placebo-controlled double-blind study. Diabetes Care. 1998;21(5):822-827.

21. Cruciani M, Lipsky BA, Mengoli C, de Lalla F. Granulocyte-colony stimulating factors as adjunctive therapy for diabetic foot infections. Cochrane Database Syst Rev. 2009;3:CD006810.

22. Cruciani M, Mengoli C, Lipsky BA, De Lalla F. Are granulocyte colony-stimulating factors beneficial in treating diabetic foot infections?: A meta-analysis. Diabetes Care. 2005;28(2):454-460.

23. Shukrimi A, Sulaiman AR, Halim AY, Azril A. A comparative study between honey and povidone iodine as dressing solution for Wagner type II diabetic foot ulcers. Med J Malaysia. 2008;63(1):44-46.

24. Hinchliffe RJ, Valk GD, Apelqvist J, et al. A systematic review of the effectiveness of interventions to enhance the healing of chronic ulcers of the foot in diabetes. Diabetes Metab Res Rev. 2008;24 Suppl 1: S119-S144.

25. Kranke P, Bennett M, Roeckl-Wiedmann I, Debus S. Hyperbaric oxygen therapy for chronic wounds. Cochrane Database Syst Rev. 2004;2:CD004123.

26. Lipsky BA, Itani K, Norden C; Linezolid Diabetic Foot Infections Study Group. Treating foot infections in diabetic patients: a randomized, multicenter, open-label trial of linezolid versus ampicillin-sulbactam/ amoxicillin-clavulanate. Clin Infect Dis. 2004;38(1):17-24.
27. Litzelman DK, Slemenda CW, Langefeld CD, et al. Reduction of lower extremity clinical abnormalities in patients with non-insulin-dependent diabetes mellitus. A randomized, controlled trial. Ann Intern Med. 1993;119(1):36-41.

28. Donohoe ME, Fletton JA, Hook A, et al. Improving foot care for people with diabetes mellitus - a randomized controlled trial of an integrated care approach. Diabet Med. 2000;17(8):581-587.

29. Malone JM, Snyder M, Anderson G, Bernhard VM, Holloway GA Jr, Bunt TJ. Prevention of amputation by diabetic education. Am J Surg. 1989;158(6):520-523; discussion 3-4.

30. Lincoln NB, Radford KA, Game FL, Jeffcoate WJ. Education for secondary prevention of foot ulcers in people with diabetes: a randomised controlled trial. Diabetologia. 2008;51(11):1954-1961.

31. Armstrong DG, Holtz-Neiderer K, Wendel C, Mohler MJ, Kimbriel HR, Lavery LA. Skin temperature monitoring reduces the risk for diabetic foot ulceration in high-risk patients. Am J Med. 2007;120(12): 1042-1046.

32. van Schie $\mathrm{CH}$, Whalley A, Armstrong DG, Vileikyte L, Boulton AJ. The effect of silicone injections in the diabetic foot on peak plantar pressure and plantar tissue thickness: a 2-year follow-up. Arch Phys Med Rehabil. 2002;83(7):919-923.

33. van Schie CH, Whalley A, Vileikyte L, Wignall T, Hollis S, Boulton AJ. Efficacy of injected liquid silicone in the diabetic foot to reduce risk factors for ulceration: a randomized double-blind placebo-controlled trial. Diabetes Care. 2000;23(5):634-638.

34. American Diabetes Association. Consensus Development Conference on Diabetic Foot Wound Care: April 7-8, 1999, Boston, Massachusetts. Diabetes Care. 1999;22(8):1354-1360.

35. Armstrong DG, Nguyen HC, Lavery LA, van Schie CH, Boulton AJ, Harkless LB. Off-loading the diabetic foot wound: a randomized clinical trial. Diabetes Care. 2001;24(6):1019-1022.

36. Boulton AJ. Pressure and the diabetic foot: clinical science and offloading techniques. Am J Surg. 2004;187(5A):17S-24S.

37. Armstrong DG, Lavery LA, Wu S, Boulton AJ. Evaluation of removable and irremovable cast walkers in the healing of diabetic foot wounds: a randomized controlled trial. Diabetes Care. 2005;28(3):551-554.

37. Katz IA, Harlan A, Miranda-Palma B, et al. A randomized trial of two irremovable off-loading devices in the management of plantar neuropathic diabetic foot ulcers. Diabetes Care. 2005;28(3):555-559.

38. Lipsky BA, Armstrong DG, Citron DM, Tice AD, Morgenstern DE, Abramson MA. Ertapenem versus piperacillin/tazobactam for diabetic foot infections (SIDESTEP): prospective, randomised, controlled, double-blinded, multicentre trial. Lancet. 2005;366(9498): 1695-1703.

39. Lavery LA, Higgins KR, Lanctot DR, et al. Home Monitoring of Foot Skin Temperatures to Prevent Ulceration. Diabetes Care. 2004;27(11):2642-2647.

40. Lavery LA, Higgins KR, Lanctot DR, et al. Preventing Diabetic Foot Ulcer Recurrence in High-Risk Patients. Diabetes Care. 2007;30(1):14-20.
International Journal of General Medicine

\section{Publish your work in this journal}

The International Journal of General Medicine is an international, peer-reviewed open-access journal that focuses on general and internal medicine, pathogenesis, epidemiology, diagnosis, monitoring and treatment protocols. The journal is characterized by the rapid reporting of reviews, original research and clinical studies across all disease areas.

\section{Dovepress}

A key focus is the elucidation of disease processes and management protocols resulting in improved outcomes for the patient. The manuscript management system is completely online and includes a very quick and fair peer-review system. Visit http://www.dovepress.com/ testimonials.php to read real quotes from published authors. 